\title{
PENGGUNAAN UNGKAPAN PERMOHONAN DALAM BAHASA JEPANG
}

\author{
Windy Galuh Pramaswari*, Ely Triasih Rahayu, Hartati \\ Program Studi Sastra Jepang, Universitas Jenderal Soedirman, Purwokerto, Indonesia
}

\begin{abstract}
This research is an analysis expressions of request in japanese language. The purpose of the research is to describe the variation of request expression and the underlying social factors. This type of research is descriptive qualitative in which the data are obtained from 3 Japanese dramas i.e From Five To Nine (5-9 Watashi ni Koi Shita Ikemen Sugiru Obousan), Shokojo Seira and Nigeru Wa Haji Da Ga. Data collection technique used observation and writing technique. Based on the result of analysis from 24 (twenty four) data, there are 5 (five) varian of request expression i.e te itakademasenka, te moraemasenka, te kudasai, te kure, and te. The underlying social factors are namely social discrepancy, social status, and formality.
\end{abstract}

Keywords:

Irai hyougen; sociolinguistics;

language variation; social

factors

\section{Article Info:}

First received:

17 November 2019

Available online:

29 May 2020

\section{PENDAHULUAN}

Manusia memerlukan bahasa sebagai alat untuk berkomunikasi dengan orang lain. Bahasa ialah sistem tanda bunyi yang disepakati untuk dipergunakan oleh para anggota kelompok masyarakat tertentu dalam bekerja sama, berkomunikasi dan mengidentifikasi diri (Yuwono, 2005:3). Hal ini juga didukung oleh beberapa pendapat yaitu Yendra (2018: 2) bahasa adalah sistem yang lebih kompleks yang terdiri dari unit-unit yang terkecil yang membentuk sebuah unit yang lebih besar yang digunakan sebagai salah satu alat berkomunikasi bagi manusia. Bahasa dikaitkan dengan masyarakat penuturnya dikaitkan juga dengan manusia sebagai makhluk sosial yang sangat memerlukan bahasa itu sendiri. Ilmu yang mengambil bahasa sebagai objek kajian yaitu ilmu linguistik.

Di dalam linguistik ada ilmu yang membahas bahasa yang berkaitan dengan masyarakat yaitu ilmu sosiolinguistik. Sosiolinguistik mengkaji bahasa dengan memperhitungkan hubungan antara bahasa dengan masyarakat, khususnya masyarakat penutur bahasa (Kunjana, 2001: 12). Didalam masyarakat terdapat aspek-aspek bahasa yaitu mengenai perbedaan dan variasi-variasi yang berkaitan dengan faktor-faktor kemasyarakatan. Menurut Soeparno (2002:25 ), "sosiolinguistik adalah subdisiplin linguistik yang mempelajari bahasa dalam kaitannya dengan faktor-faktor kemasyarakatan atau faktor sosial."

Masalah yang dikaji dalam sosiolinguistik antara lain mengkaji aspek sosial dan kebudayaan, menghubungkan faktor-faktor kebahasaan antara lain: ragam bahasa, situasi, faktor-faktor sosial dan budaya serta mengkaji fungsi-fungsi sosial dan penggunaan bahasa dalam masyarakat. Jadi dapat disimpulkan bahwa sosiolinguistik adalah ilmu yang mempelajari bahasa dengan faktor-faktor yang ada di dalam masyarakat penutur bahasa. Masyarakat Jepang sangat memperhatikan bahasa. Mempunyai ragam bahasa sopan yang berbedabeda mereka sangat memperhatikan kepada siapa mereka berbicara, dimana mereka berbicara dan ragam bahasa sopan yang bagaimana yang dipakai tujuannya agar lawan tutur merasa dihormati dan melakukan apa yang penutur minta. Pemakaian bahasa juga dipengaruhi oleh faktor-faktor situasional, yaitu siapa berbicara dengan bahasa apa, kepada siapa, kapan dan dimana. 


\section{TINJAUAN PUSTAKA}

\section{Sosiolinguistik}

Manusia pada hakekatnya adalah makhluk sosial. Tidak bisa hidup sendiri pasti membutuhkan orang lain dalam kehidupannya. Kehidupan di dalam masyarakat erat kaitannya dengan komunikasi antar sesama yang pasti melibatkan bahasa. Ilmu yang membahas hubungan bahasa dengan masyarakat adalah sosiolinguistik. Seperti yang sudah dibahas pada bab pendahuluan. Sosiolinguistik merupakan cabang ilmu linguistik yang didalamnya mengkaji dan membahas bahasa yang erat kaitannya dengan faktor sosial dan budaya yang ada di dalam masyarakat penutur bahasa.

\section{Faktor Sosial dalam Variasi Bahasa}

Penggunaan bahasa pada masyarakat penutur bahasa tidak hanya ditentukan oleh faktor-faktor bahasanya saja melainkan juga ditentukan oleh faktor nonbahasa yaitu faktor sosial. Faktor sosial dalam variasi bahasa sangat mempengaruhi pemilihan variasi bahasa yang digunakan. Misalnya: status sosial, tingkat pendidikan, umur, jabatan, tingkat ekonomi, jenis kelamin, dan faktor-faktor sosial lainnya. Hal ini sejalan dengan pendapat Kabaya (dalam Rahayu, 2017:5)

コミュニケーションをする時に、コミュニケ ーション主体（話し手、書き手、聞き手、読 み手）が（場面（人間関係、場））のことを 考える。

Komunikeeshon o suru toki ni, komunikeeshon shutai (hanashite, kakite, kikite, yomite) ga (bamen (ningenkankei, ba)) no koto o kangaeru.

'Ketika berkomunikasi, pelaku komunikasi (pembicara, penulis, pendengar, pembaca) harus memperhatikan (latar (hubungan antarpelaku komunikasi dan tempat).'

Status sosial dapat dilihat dari pekerjaan atau kedudukan seorang penutur.Contoh ungkapan terimakasih memiliki variasi ungkapan: doumo, arigatou gozaimasu, dan doumo arigatou gozaimasu. Doumotidak tepat diucapkan oleh anak kepada orangtuanya. Doumo digunakan kepada seseorang yang sebaya atau seusia. Apabila ingin mengucapkan terimakasih kepada orangtua gunakan arigatou gozaimasu saja sudah cukup karena hubungan antara anak dan orangtua sangat dekat. Ungkapan doumo arigatou gozaimasu tepat digunakan oleh murid kepada gurunya, karena guru adalah seseorang yang sangat dihormati di sekolah.

Dell Hymes (dalam Rusminto, 2010:57) mengatakan bahwa peristiwa tutur harus memenuhi delapan komponen, yang dikenal dengan SPEAKING. Kedelapan komponen tersebut adalah:

1. S (Setting and Scene)

Waktu, tempat, dan situasi yang berbeda dapat menyebabkan penggunaan variasi bahasa yang berbeda.

Ada dua macam situasi dalam pembicaraan yaitu,

a) Situasi Formal

Situasi ini partisipan untuk menggunakan bahasa baku atau standar. Situasi seperti ini sering kita jumpai pada pidato kenegaraan, wawancara pekerjaan, pertemuan dinas dll.

b) Situasi Non Formal

Situasi ini partisipan cenderung menggunakan variasi bahasa yang diinginkannya dalam percakapan. Mereka lebih memilih menggunakan variasi bahasa tidak baku dan non formal dalam tuturannya untuk membuat suasana lebih akrab. Waktu, tempat dan situasi yang berbeda dapat menyebabkan penggunaan bahasa yang berbeda. Situasi pembicaraan di sebuah pasar antara pedagang dan pembeli akan sangat berbeda dengan pembicaraan di sebuah ruang rapat anggota DPR. Situasi pembicaraan di pasar sangat informal sedangkan situasi pembicaraan di ruang rapat DPR akan menggunakan bahasa baku dan situasi yang sangat formal.

\section{2. $\mathrm{P}$ (Participants)}

Pihak-pihak yang terlibat dalam petuturan, bisa pembicara dan pendengar, penyapa dan pesapa atau pengirim pesan dan penerima pesan, hal ini mempengaruhi pemilihan variasi bahasa diantara mereka dipengaruhi oleh:

a) Jarak sosial, mengacu pada seberapa baik kita mengenal mitra tutur.

Hal ini merupakan faktor penting yang menentukan bagaimana cara 
kita berbicara dengan mitra tutur kita. Ada dua jenis hubungan dalam hal ini yaitu hubungan akrab atau intimate dan hubungan jauh atau distant. Hubungan dekat biasa digunakan oleh orang - orang yang mengenal dengan baik, sedangkan hubungan jauh digunakan oleh orang - orang yang baru saling mengenal.

b) Status sosial, mengacu pada kedudukan seseorang dalam suatu masyarakat. Tinggi rendahnya status seseorang dapat ditentukan oleh jabatan atau pekerjaan, latar belakang ekonomi, politik, pendidikan maupun keturunan yang terbagi atas status sosial lebih tinggi atau superior dan status sosial lebih rendah atau subordinat. Seorang penutur akan berusaha menggunakan bentuk bahasa yang lebih sopan dan baku apabila berinteraksi dengan orang yang statusnya lebih tinggi dan sebaliknya seseorang yang lebih tinggi statusnya akan cenderung menggunakan bahasa yang lebih sederhana dengan orang yang status sosialnya lebih rendah contohnya hubungan antara karyawan dan atasan.

\section{E (Ends: Purpose or Outcomes and Goal)}

Merujuk pada maksud dan tujuan pertuturan peristiwa yang diharapkan. Outcomes adalah tujuan dari peristiwa bahasa yang dilihat dari sudut pandang kebudayaan, sedangkan goals adalah tujuan dari para partisipan itu sendiri. Contoh dalam peristiwa perdagangan, outcomes-nya adalah pertukaran suatu barang dari satu pihak ke pihak lain, sedangkan goalsnya bagi pedagang adalah mendapatkan laba sebesar-besarnya, dan bagi para pembeli adalah memperoleh barang semurah-murahnya.

\section{A (Act Sequences)}

Merujuk message form dan message content. Message form atau bentuk pesan adalah cara bagaimana kita mengungkapkan suatu topik atau informasi. Bentuk tersebut tergantung pada situasi, sedangkan message content atau isi pesan adalah apa yang kita katakan. Misalnya: bentuk ujaran dalam perkuliahan, dalam percakapan biasa dan dalam pesta pasti berbeda. Begitu juga dengan isi yang dibicarakan.

5. K (Key: Tone or Spirit of Act)

Mengacu pada cara, nada dan jiwa semangat di mana suatu pesan disampaikan. Kunci itu kira-kira serupa dengan modalitas dalam kategori gramatika. Suatu peristiwa tindak tutur bisa berbeda dengan kunci. Misalnya antara serius dan santai, hormat dan tidak hormat, sederhana dan angkuh, dan sebagainya. Hal ini ditujukan dengan gerak tubuh dan isyarat seperti kedipan mata, gaya berpakian, bahasa tubuh, dan sebagainya.

6. I (Instrumentalities)

Mengacu pada jalur bahasa yang digunakan, seperti jalur lisan, tertulis, melalui telegraf atau telepon. Dalam hal saluran, orang harus membedakan cara menggunakannya. Saliran lisan (oral), misalnya dipakai untuk bernyanyi, bersenandung, bersiul, mengujarkan tuturan, dan lain-lain. Ragam lisan untuk tatap muka berbeda dengan untuk telepon, ragam tulis untuk telegram berbeda dengan ragam tulis surat, dan sebagainya.

7. $\mathrm{N}$ (Norm of Interaction and Interpretation)

Mengacu pada norma atau aturan yang digunakan dalam interaksi.

8. $\mathrm{G}$ (Genres)

Mengacu pada jenis bentuk atau register khusus yang digunakan dalam peristiwa tutur. Penelitian ini leih ditekankan pada faktor-faktor sosial apa saja yang mempengaruhi penggunaan variasi ungkapan permohonan dalam bahasa Jepang. Faktor-faktor tersebut difokuskan pada penutur dan mitra tutur, situasi yang melingkupi terjadinya tuturan, jarak sosial, status sosial, dan formalitas.

Variasi penggunaan bahasa di antaranya ditentukan dimensi atau faktor-faktor sosial, yaitu:

\section{Skala Jarak Sosial}

Jarak sosial erat kaitannya dengan penutur dan mitra tutur yaitu tampak dari tingkat keakraban hubungan antara penutur dan mitra tutur sangat ditentukan oleh intensitas hubungan diantara keduanya. Intensitas hubungan yang tinggi akan membuat tingkat keakraban hubungan menjadi dekat, sebaliknya intensitas hubungan yang kurang atau rendah membuat tingkat keakraban hubungan menjadi jauh. 


\section{Skala Status Sosial}

Faktor sosial ini sangat ditentukan oleh peran status sosial yang didalamnya meliputi kedudukan, tataran, tingkat, derajat atau martabat sosial terhadap orang lain.

Holmes (dalam Rusminto, 2010:52) menjelaskan bahwa status yang dimiliki seseorang menentukan supremasi orang tersebut dalam berkomunikasi. Contohnya tuturan anak kepada kakeknya, jika dilihat dari status sosial dan usia, kakek memiliki usia yang jauh lebih tua dan secara status sosial dan kedudukan kakek tentunya lebih tinggi dari si anak atau cucu dalam hal ini.

3. Skala Formalitas

Kegiatan berkomunikasi erat kaitannya dengan waktu dan tempat terjadinya peristiwa tutur. Ada dua macam situasi dalam pembicaraan. Yaitu situasi formal dan tidak formal.

\section{Variasi Bahasa}

Penggunaan bahasa erat kaitannya dengan masyarakat. Oleh karena itu bahasa dipengaruhi oleh pemakai bahasa. Pengaruh yang dimaksud adalah pengaruh situasi dalam konteks sosialnya. Hal ini menyebabkan adanya variasi bahasa di dalam masyarakat. Menurut Pateda (1990: 52), variasi bahasa dilihat dari segi tempat, segi waktu, segi pemakai, segi pemakainya, segi situasi, dan dari status sosialnya. Dalam variasi bahasa terdapat pola-pola bahasa yang sama, pola-pola bahasa itu dapat dianalisis secara deskriptif, dan pola-pola yang dibatasi oleh makna tersebut dipergunakan oleh penuturnya untuk berkomunikasi.

\section{Irai hyougen}

Dalam bahasa Jepang memohon disebut dengan irai. Iori menjelaskan irai sebagai berikut: 依頼とは話し手の利益のために何らかの行為を すること（しないこと）を聞き手に頼む表現で す。

Irai to ha hanashite no rieki no tame ni nanraka no koui wo suru kooto (shiranai kkoto) wo kikite ni tanomu hyougen desu.

Irai adalah ungkapan untuk meminta lawan tutur untuk melakukan atau tidak melakukan sesuatu yang diminta oleh penutur. Ungkapan permohonan dalam bahasa Jepang disebut irai hyougen. Masyarakat Jepang sangat memperhatikan unggah ungguh bahasa.mereka sangat memperhatikan apa yang mereka ucapkan, untuk meminta tolong ataupun menyuruh kepada seseorang sangat memperhatikan pemilihan variasi bahasanya.

Iori (2000:148 ) membagi bentuk memohon menjadi 7 yaitu, (a) te Kudasai , (b) $\sim$ te kudasaimasenka, (c) te kuremasenka, (d) te moraemasenka, (e) te itadakemasenka, (f) $\sim$ te kure, (g) te .

(a) Bentuk Te Kudasai ( てくださ () Bentuk sopan yang digunakan kepada orang yang mempunyai hak/pangkat yang sama atau orang yang lebih rendah kedudukannya, dalam pengungkapan makna permohonan $\sim$ te kudasai biasa digunakan kepada orang yang belum akrab serta untuk memperhalus bahasa yang digunakan.

(b) Bentuk $\sim$ Te Kudasaimasenka ( て くださいませんか) Bentuk Te Kudasaimasenka adalah ungkapan untuk mengungkapkan makna permohonan sesuai dengan apa yang dimaksud oleh pendengar. Maksudnya sesuai dengan apa yang menjadi lumrah menurut pemikiran si lawan bicara. Ungkapan ini mempunyai tingkat kesopanan yang tinggi, dan juga merupakan permohonan yang memberi beban yang berat kepada lawan bicara dan juga ungkapan yang dipakai untuk memohon kepada orang yang lebih tinggi yang sebenarnya kita tidak pantas untuk meminta pertolongan.

(c) Bentuk $\sim$ Te kuremasenka

(d) Bentuk $\sim$ Te moraemasenka tingkatannya lebih tinggi dan lebih sopan dari bentuk $\sim$ Te Kudasai dan $\sim$ Te Kudasaimasenka

(e) $\quad \sim$ Te itadakemasenka memiliki tingkatan lebih tinggi dan lebih sopan dari bentuk $\sim T e$ Kudasai dan $\sim$ Te Kudasaimasenka 
(f)

Bentuk $\sim$ Te Kure $(\sim \tau<れ)$ Merupakan bentuk biasa dari $\sim T e$ kudasai. Ungkapan ini juga di ucapkan secara langsung kepada lawan bicara. Ungkapan $\sim T e$ Kure biasanya di pakai oleh lelaki ketika lawan bicaranya keluarga, teman yang dekat/akrab.

(g) Bentuk $\sim T e(\sim \tau)$ Sama seperti bentuk $\sim T e$ Kure, hanya saja penggunaannya tidak dibatasi gender. Laki-laki maupun perempuan bisa menggunakan ini.

\section{METODE PENELITIAN}

Penelitian ini merupakan penelitian deskriptif kualitatif yaitu penelitian yang datanya adalah data kualitatif sehingga analisisnya juga analisis deskriptif. Senada dengan pendapat tersebut Sukmadinata (2009:18) berpendapat bahwa data kualitatif adalah data dalam bentuk kata, kalimat, dan gambar. Untuk memperoleh data kualitatif peneliti diharuskan mempunyai banyak waktu serta usaha yang lebih karena untuk mencari data yang diperoleh dengan melakukan wawancara, observasi atau pengamatan. Penelitian ini bertujuan memaparkan bentuk-bentuk serta faktor sosial yang melatarbelakangi penggunaan ungkapan permohonan didalam bahasa Jepang.

Data dalam penelitian ini berupa ungkapan-ungkapan yang diwujudkan dalam percakapan dari para tokoh yang ada dalam drama yang mengandung unsur ungkapan permohonan dengan memperoleh data sebanyak 85 yang meliputi te kudasai sebanyak 44 data, te kure sebanyak 23 data, te itadakemasenka sebanyak 3 data, te sebanyak 13 data dan te moraemasenka sebanyak 2 data. Penulis memakai 24 sampel data yang digunakan untuk menganalisis penelitian. Penulis menemukan faktor sosial yang melatarbelakangi penggunaan ungkapan permohonan yaitu: skala jarak sosial, skala status sosial dan skala formalitas.

Sumber data dalam penelitian ini terdiri dari beberapa drama yaitu antara lain drama From Five To Nine $(5 \rightarrow 9$ : Watashi ni Koi Shita Ikemen Sugiru Obousan) yang disutradarai oleh Shin Hirano dengan jumlah episode 10 yang dirilis tanggal 12 Oktober sampai 14 Desember
2015 di siarkan oleh Fuji TV yang kedua penulis menggunakan transkripsi drama Shokojo Seira yang berjumlah 10 episode yang disutradarai oleh Fuminori Kaneko dan Akio Yoshida yang berjumlah 10 episode yang dirilis tanggal 17 Oktober 2009 sampai 19 Desember 2009 yang berjumlah 10 episode dan yang terakhir penulis menggunakan transkripsi drama Nigeru Wa Haji Da Ga yang berjumlah 11 episode yang disutradarai oleh Fuminori Kaneko yang menyatakan ungkapan Irai.

Teknik pengumpulan data yang digunakan dalam penelitian ini adalah metode simak dan teknik catat. Metode simak menurut Mahsun (2007:92) yaitu cara yang digunakan untuk memperoleh data dilakukan dengan menyimak penggunaan bahasa. Istilah menyimak di sini tidak hanya berkaitan dengan penggunaan bahasa secara lisan, tetapi juga penggunaan bahasa secara tertulis. Semua data yang sudah terkumpul akan di analisis setelah data itu di klasifikasikan.

\section{HASIL DAN PEMBAHASAN}

$\mathrm{Bab}$ ini berisi tentang uraian pembahasan bentuk-bentuk ungkapan permohonan beserta faktor-faktor sosial yang mempengaruhi penggunaan ungkapan di dalam drama From Five To Nine $(5 \rightarrow 9$ : Watashi ni Koi Shita Ikemen Sugiru Obousan), Shokojo Seira, dan Nigeru Wa Haji Daga. Penulis menemukan 85 tuturan ungkapan permohonan. Ungkapan permohonan tersebut berjumlah lima jenis variasi yaitu: te kudasai, te kure, te, te moraemasenka, dan te itadakemasenka.

Berdasarkan penelitian terhadap drama tersebut, ditemukan faktor-faktor sosial yang mempengaruhi tuturan variasi ungkapan permohonan meliputi, aspek jarak sosial, status sosial, formalitas. Ditemukan empat skala aspek sosial mitra tutur dengan hubungan sangat dekat, aspek sosial mitra tutur dengan hubungan cukup dekat, aspek sosial mitra tutur cukup jauh, aspek sosial mitra tutur dengan hubungan sangat jauh. Status sosial meliputi status sosial dari tinggi ke rendah begitupun sebaliknya lalu yang terakhir skala formalitas ditemukan skala formalitas formal dan non formal. 
1. Skala Jarak Sosial

a. Skala Jarak Sosial Hubungan Sangat Jauh

DATA1 Konteks:

Penutur : Kaori Ashigaka (KA)

Mitra Tutur :Sakuraba Junko (SJ)

Tempat : ELA

Situasi :Kaori Ashigaka memohon kepada

Sakuraba Junko untuk menjauhi Takane

KA ：高嶺さまと結婚寸る気がおあり

なのですか? もしないのなら思わせぶりな態

度はやめていただけませんか?

Takane-sama to kekkon suru ki ga oarina no desuka? Mo shinai nonara, Omowaseburina taido wa yamete itadakemasen $k a$

'Apa kau berniat menikahi bapak Takane? Jika tidak, mohon tolong hentikan tingkah lakumu yang seperti memberi harapan?'

SJ ：星川さんと結婚する気はありま せん

Hoshikawa-san to kekkon suru $k i$ wa arimasen

'Saya tidak mau menikahi bapak Hoshikawa'

(From Five to Nine eps 05 detik ke 22:14-22:18)

Data tersebut terjadi di ruang pertemuan ELA. Mitra tutur KA merupakan orang yang akan dijodohkan dengan Hoshikawa, namun Hoshikawa tidak menerima cintanya dan lebih mencintai SJ. Lalu KA sangat memohon kepada SJ agar menghentikan tingkah laku yang memberi harapan kepada Hoshikawa.

Tuturan diatas terjadi antara mitra tutur dan penutur yang memiliki status jarak sosial hubungan sangat jauh karena keduanya belum mengenal sama sekali dan belum pernah bertemu sebelumnya. KA memilih ragam ungkapan te itadakemasenka. Ungkapan memohon ini merupakan bentuk kenjougo karena di dalam tuturan tersebut KA sangat memohon kepada SJ untuk menjauhi Hoshikawa dan penutur merasa permohonan ini akan terasa berat untuk dilakukan sehingga penutur memilih menggunakan bentuk ungkapan permohonan tersebut untuk memohon kepada mitra tutur. b. Skala Jarak Sosial Hubungan Cukup Jauh.

DATA 5 Konteks :

Penutur : Tsuzaki (T)

Mitra Tutur : Mikuri Moriyama (MM)

Tempat : Rumah Tsuzaki

Situasi :Tsuzaki yang sedang mencari asisten rumah tangga bertemu untuk pertama kalinya dengan Mikuri. Tsuzaki meminta Mikuri untuk membersihkan rumahnya.

$\mathrm{T}$ : 掃除はきっちりしてください水回りは 重点的に空ふきもお願いしますこれ今日の分 の料金です

Sōji wa kitchiri shite kudasai mizu mawari wa jütenteki ni mado fuki mo onegaishimasu kore kyō no bun no ryōkindesu

'Tolong bersihkan dengan baik, hati-hati dengan area yang basah dan tolong lap jendelanya juga. Ini bayaran untukmu hari ini'

$\mathrm{MM}$ : 前払いですか?

Maebaraidesu ka?

'Aku dibayar dimuka?'

Nigeru Wa Haji Daga eps 01 detik ke 08:55-09:04

Peristiwa tutur diatas terjadi dirumah Tsuzaki dimana ia bertemu dengan Mikuri untuk pertama kalinya, Tsuzaki merupakan teman ayah dari Mikuri. Ayah Mikuri sering menceritakan Tsuzaki kepada Mikuri. Tsuzaki saat ini sedang mencari asisten rumah tangga untuk rumahnya dan kebetulan Mikuri sedang mencari pekerjaan baru setelah ia dipecat di perusahaan tempatnya bekerja. Tsuzaki meminta Mikuri untuk membersihkan rumahnya.

Pada tuturan diatas penutur dan mitra tutur secara psikologis mempunyai jarak sosial hubungan cukup jauh dimana keduanya belum saling mengenal dan baru pertama kali bertemu, tetapi dalam konteks ini Mikuri sudah sering mendengar ayahnya bercerita mengenai Tsuzaki sehingga walaupun keduanya memiliki status sosial hubungan cukup jauh keduanya sudah tidak canggung dan mudah akrab satu sama lain. Ungkapan memohon yang muncul pada peristiwa tutur diatas adalah te kudasai karena walaupun memiliki status sosial hubungan cukup jauh tetapi mereka masih sepantaran usia. 
c. Skala Jarak Sosial Hubungan Sangat Dekat.

DATA 8 Konteks :

Penutur : Tochio / ayah mikuri (T)

Mitra Tutur : Sakura (S) / Ibu Mikuri

Tempat : Rumah

Situasi : Ayah Mikuri meminta istrinya untuk melihat rencana renovasi rumah mereka yang berada di desa.

$\mathrm{T}$ ：ちよっとここ見て桜さんがほしがって た縁側改修後はプランがこっち

Chotto koko mite sakura-san ga hoshi gatteta engawa kaishü-go wa puran ga kotchi

'Lihat ini, sesuai apa yang kamu minta sakura-san, ini rencana renovasinya"

S : 仕事早 W

Shigoto hayai

'Kau cepat sekali'

Nigeru Wa Haji Daga eps 01 detik ke 22:35-22:40

Pada data diatas terjadi di rumah Mikuri saat mereka sedang makan malam, penutur yaitu ayah mikuri ingin memiliki rumah di desa dengan suasana alam dan sejuk lalu ia meminta kepada istrinya untuk melihat rencana renovasi rumah mereka yang ada di desa nantinya.

Peristiwa tuturan diatas berlangsung antara suami dan istri yang secara psikologis mereka mempunyai jarak hubungan sangat dekat oleh karena itu ungkapan permohonan yang muncul tergolong santai dan non formal yaitu te.

d. Skala Jarak Sosial Hubungan Cukup Dekat.

DATA 10 Konteks :

Penutur : Makoto Kiyomiya (MK)

Mitra Tutur : Sakuraba Junko (SJ)

Tempat : Klub malam

Situasi : Di sebuah klub malam para karyawan ELA sedang mengadakan pesta penyambutan manager baru mereka. Makoto Kiyomiya memohon kepada Sakuraba agar saat ia melakukan kesalahan, Sakuraba tidak sungkan untuk memberitahunya.

MK ：前は俺の生徒だったのにまさかホント に講師になってるとはな。もう何年?

Mae wa ore no seitodattanoni masaka honto ni kōshi ni natteruto Hana. Mō nan-nen?
'Kau dulu muridku, tapi sekarang sudah jadi pengajar. Sudah berapa tahun ?'

SJ : 2 年たちました。

2 nentachimashita.

'Sudah 2 tahun'

MK：頼もしいな桜庭先生。俺に間違いや不 満があるときは言ってくれ。

Tanomoshī na Sakuraba sensei. Ore ni machigai ya fuman ga aru toki wa itte kure.

'Luar biasa, Sakuraba sensei jika aku melakukan kesalahan, tolong jangan ragu memberitahuku'

From Five to Nine eps01 detik 27:12-27:19

Di sebuah klub malam mereka mengadakan pesta penyambutan general manager yang baru yang merupakan mantan pengajar Sakuraba yang juga menjadi sahabatnya. Ditengah tengah acara Makoto Kiyomiya menemui Sakuraba dan mengobrol bersama, Makoto Kiyomiya meminta kepada Sakuraba jika ia melakukan kesalahan nantinya Sakuraba tidak sungkan untuk memberitahunya.

Tuturan terjadi antara mitra tutur dan penutur yang merupakan sahabat lama, secara kedekatan emosi mereka memiliki skala jarak sosial hubungan cukup dekat oleh karena itu pemilihan bentuk ungkapan permohonan yang digunakan adalah te kure. te kure pada penggunaannya merupakan ragam bahasa informal yang biasa digunakan pada percakapan santai sehari-hari. Bentuk ungkapan memohon ini merupakan ragam bahasa pria (danseigo).

\section{Skala Status Sosial}

a. Skala Status Sosial dari Tinggi ke Rendah

DATA 14 Konteks:

Penutur : Makoto Kiyomiya (MK)

Mitra Tutur : Sakuraba Junko (SJ)

Tempat : Jalan

Situasi :Makoto Kiyomiya meminta Sakuraba untuk ikut dengannya ke New York MK : 桜庭。俺と一緒にニューヨークへ行っ てくれ。

Sakuraba. Ore to issho ni nyūyōku e itte kure York' 'Sakuraba, ikutlah bersamaku ke New SJ : えっ? 
Eee

'Haa'

From Five to Nine eps 04 detik ke 44:52-44:55

Di sebuah jalanan di kota Tokyo. Makoto Kiyomiya dan Sakuraba hendak pulang dari ELA. Makoto Kiyomiya memohon kepada Sakuraba untuk ikut dengannya ke New York untuk menjadi pengajar disana. Hal ini dikarenakan Makoto Kiyomiya tidak ingin Sakuraba terus dekat dengan Hoshikawa.

Penutur yang merupakan manager ELA dan mitra tutur yang merupakan pengajar yang memiliki skala hubungan cukup dekat. Penutur menggunakan bentuk ungkapan memohon te kure karena penutur memiliki status sosial lebih tinggi dari mitra tutur yang merupakan pengajar. Bentuk ungkapan ini juga merupakan ragam bahasa pria yang sering di gunakan dalam percakapan informal.

\section{b. Skala Status Sosial dari Rendah ke Tinggi}

DATA 19 Konteks:

Penutur : Kaito (K)

Mitra Tutur : Seiichiro Owada (SO)

Tempat : Dapur

Situasi :Kaito sedang bekerja didapur. Ia ingin meminta izin kepada Seiichiro Owada untuk pergi ke paruh waktu sekolah tinggi yang ia inginkan.

SO : おい カイト！片づけと仕込みち やんとやっとけよ yattoke yo

Oi Kaito! Katadzuke to shikomi chanto

'Oi Kaito! Kau harus bersihkan ini dan ambil persediaan'

$\begin{array}{ll}\mathrm{K} & \text { : はい あッ あの... } \\ & \text { Haia ano } \\ & \text { 'Baik, aaa ummm...' } \\ \mathrm{SO} & \text { : 何だよ? } \\ & \text { Nanda yo? } \\ & \text { 'Apa ini?’ } \\ \mathrm{K} & \text { :もう一度 頼んでいただけませんか }\end{array}$
定時制の高校に通うこと

Mōichido tanonde itadakemasen ka teijisei no kōkō ni kayou koto

'Saya mohon sekali lagi, bolehkan saya pergi ke sekolah?'

(Shokojo Seira eps 01 menit ke 31:23-31-29)

Peristiwa tutur pada percakapan diatas terjadi di dapur sekolah dimana penutur Kairo sedang bekerja seperti biasanya, mitra tutur Seiichiro menyuruh Kaito untuk membersihkan dan mempersiapkan sarapan untuk para murid. Ditengah-tengah percakapan Kaito memohon kepada Seiichiro untuk bisa pergi ke sistem sekolah tinggi paruh waktu yang ia inginkan.

Pada data diatas peristiwa tutur terjadi antara Kaito dan Seiichiro yang merupakan kepala chef di dapur sekolah yang memiliki status sosial lebih tinggi dari Kaito dilihat juga dari perbedaan usia mereka yang cukup jauh. Variasi ungkapan permohonan yng digunakan oleh Kaito juga merupakan ragam bahasa hormat yang sering digunakan dalam percakapan sehari-hari untuk memperhalus bahasa dan menghormati lawan bicara.

\section{c. Skala formalitas \\ a. Skala Formal}

DATA 20 Konteks:

Penutur : Makaso Maori (MM)

Mitra Tutur : Calon Murid (CM)

Tempat : Bagian Informasi ELA

Situasi :Makaso Maori menawarkan kepada calon murid ELA jika ingin membuat janji untuk kursus bahasa inggris dimohon menghubungi dirinya.

MM：うちには世界的にもトップレベルの先 生が揃っています。レッスンの予 約をする 際は私に声を掛けてくださいね

Uchi ni wa sekai-teki ni mo toppu reberu no sensei ga sorotte imasu. Ressun no yoyaku o suru sai wa watashi ni koe o kakete kudasai ne

'Pengajar bertaraf internasional berkumpul ditempat kami, jika ingin membuat janji untuk kursus silahkan hubungi aku.'

$\mathrm{CM}$ :君は予約できないの?

Kimi wa yoyaku dekinai no?

'Bisakah aku membuat janji denganmu?'

(From Five to Nine eps 1 detik ke 05:21-05:3)

Penutur bekerja di pusat informasi ELA. Percakapan diatas terjadi di tempat kerja penutur, tuturan dilakukan antara penutur yang seorang resepsionis dengan calon siswa kursus. Makaso meminta kepada calon murid agar 
kalau dirinya ingin membuat janji kursus dimohon untuk menghubunginya.

Peristiwa tutur yang terjadi pada situasi formal dimana peristiwa tutur terjadi di kantor bagian informasi, ragam ungkapan te kudasai digunakan karena penutur dan mitra tutur masih sepantaran usia dan belum mengenal satu sama lain.

\section{b. Skala non formal}

DATA 22 Konteks:

Penutur : Sakuraba Junko (SJ)

Mitra Tutur: Hoshikawa (H)

Tempat : Rumah Sakuraba

Situasi :Ketika Sakuraba dan Hoshikawa sedang membicarakan rencana kencannya besok, keluarga Sakuraba berisik sehingga mengganggu mereka, lalu Sakuraba meminta ayah, ibu dan adiknya untuk diam.

SJ : 違うんです。星川さん。

Chigaundesu. Hoshikawa

'Bukan, Hoshikawa'

$\mathrm{H}$ : 集合は 1 時でよろしいですか?

Shūgō wa 1-ji de yoroshīdesu ka?

'Bisakah kita bertemu pukul 1?'

SJ : そういうことではなくて。ああー！失 敗した。

ちょっと静かにして。

Sō iu kotode wanakute. $\bar{A}^{-}$! Shippaishita. Chotto shizukani shite.

'Bukan itu, Tolong tenang!'

(From Five to Nine eps 05 detik ke 23:27-23:31)

Percakapan diatas terjadi dirumah Sakuraba, ibu bersama ayah dan adik Sakuraba sedang memasak okonomiyaki untuk makan malam keluarga dan menimbulkan suasana gaduh. Sakuraba dan Hoshikawa sedang membicarakan rencana kencan mereka besok, terganggu dengan suara brisik mereka lalu menyuruh mereka diam.

Pada data diatas terjadi di situasi informal yaitu dirumah Sakuraba. Sakuraba memilih menggunakan bentuk ungkapan memohon te karena berbicara kepada seseorang yang sudah akrab serta situasinya informal.

\section{KESIMPULAN}

1. Variasi ungkapan permohonan yang muncul dalam drama tersebut diatas adalah 5 jenis meliputi: te itadakemasenka, te moraemasenka, te kudasai, te kure, dan te. Penulis tidak menemukan 2 jenis variasi ungkapan permohonan yang lain menurut teori Isao Iori yaitu te kuremasenka dan te kudasaimasenka karena tidak relevan dengan sumber data.

2. Faktor sosial yang melatarbelakangi variasi ungkapan permohonan yang digunakan meliputi: jarak sosial, status sosial, dan skala formalitas.

\section{DAFTAR PUSTAKA}

Ananda, Prita. 2015. Faktor Sosial Variasi

Ungkapan Maaf dalam Bahasa Jepang. 2015.

Universitas Jenderal Soedirman.

Chaer, Abdul. 2013. Linguistik umum. Jakarta: PT Rineka Cipta.

Chaer, Abdul dan Agustina. 1995.

Sosiolinguistik: Perkenalan Awal. Jakarta: PT

Rineka Cipta.

Fitrati, Rekha Della. 2014. Ungkapan Ajakan Dalam Bahasa Jepang Dan Bahasa Indonesia. Jakarta. Universitas Pendidikan Indonesia.

Hiejima, Ichiro. 1992. Kotoba to Shakai. Tokyo: Gyoosei.

Hudson, R.A. 1996. Sociolinguistics. Cambrige: Cambrige University Press.

Isao, Iori,dkk. 2000. Nihongo Bunpou Handobukku. Japan: 3A Corporation

Kridalaksana, Harimurti. 2008. Kamus Linguistik. Jakarta: Gramedia Pustaka Utama.

Kunjana, R. Rahardi. 2001. Sosiolinguistik Kode dan Alih Kode. Yogyakarta: Pustaka Pelajar Offset

Lindiasari, Irlyana Seftya. 2014. Kesantunan Ungkapan Permintaan Maaf Bahasa Jepang. Malang. Universitas Brawijaya.

Mansoer, Pateda. 1990. Sosiolinguistik. Yogyakarta : Gadjah Mada University Press

Moleong, Lexy J. 2015. Metodologi Penelitian Kualitatif. Bandung: PT Remaja Rosdakarya.

Nababan. 1989. "Sosiolinguistik dan Pengajaran Bahasa" dalam PELLBA 2. 
Jakarta: Lembaga Bahasa Unika Atma Jaya.

1993. Sosiolinguistik: Suatu Pengantar. Jakarta: Gramedia Pustaka Utama.

Nakao Toshio, Hibiya Junko, et al. 1997. Shakai Gengogaku Gairon - Nihongo to Eigo norei de Manabu Shakai Gengogaku. Tokyo : Kuroshio Shuppan.

Narbuko, Cholid dan Achmadi, Abu. 2013. Metodologi Penelitian, Jakarta: PT. Bumi Aksara.

Putra, Jeni. 2014. Strategi Tindak Tutur Permohonan Pembelajar Bahasa Jepang Tingkat Mahir. Jakarta: Universitas Pendidikan Indonesia.

Rusminto, Nurlaksana Eko. 2015. Analisis Wacana: Kajian Teoritis dan Praktis. Yogyakarta: Graha Ilmu

Satyanto. 2015. Variasi Strategi Kesantunan Permintaan Bahasa Jepang Dalam Drama Engine. Semarang. Universitas Dian Nuswantoro.
Sihombing, P Liberty. dkk. 2005. Pesona bahasa. Jakarta: PT Gramedia Pustaka Utama.

Soeparno. 2002. Dasar-dasar Linguistik Umum. Yogyakarta: PT Tiara Wacana.

Sukmadinata, Nana S. 2009. Metode Penelitian Pendidikan. Bandung: PT. Remaja Rosdakarya.

Sutedi, Dedi. (2004), Dasar-Dasar Linguistik Bahasa Jepang. Bandung: Humaniora.

Triasih, Ely. 2017. Konstruksi Tuturan Bahasa Jepang. Erhaka Utama. Yogyakarta

Yuwono, Untung. 2005. Pesona bahasa. Jakarta: PT Gramedia Pustaka Utama.

Yendra. 2018. Mengenal Ilmu Bahasa. Sumatera Barat.

Zulaikha Ita. 2013. Jurnal Tindak Tutur Memohon Bahasa Jepang dalam Buku Nameraka Nihongo Kaiwa. Riau 